\title{
Soluble CD26 levels and its association to epidemiologic parameters in a sample population
}

\author{
Loretta De Chiara $^{\mathrm{a}}$, Ana M. Rodríguez-Piñeiro ${ }^{\mathrm{a}}$, Oscar J. Cordero ${ }^{\mathrm{b}}$, Francisco J. Rodríguez-Berrocal ${ }^{\mathrm{a}}$, \\ Daniel Ayude ${ }^{\mathrm{a}}$, Francisco J. Rivas-Hervada ${ }^{\mathrm{c}}$ and María Páez de la Cadena ${ }^{\mathrm{a}, *}$ \\ ${ }^{a}$ Universidad de Vigo, Facultad de Biología, Departamento de Bioquímica, Genética e Inmunología, As \\ Lagoas-Marcosende s/n, 36310 Vigo, Spain \\ ${ }^{\mathrm{b}}$ Universidad de Santiago de Compostela, Facultad de Biología, Departamento de Bioquímica y Biología \\ Molecular, San Francisco s/n, Campus Universitario Norte, 15782 Santiago de Compostela, Spain \\ ${ }^{c}$ Peugeot Citroën Automóviles España, S.A. Centro de Vigo, Servicio Médico, Av. Citroën 3 y 5, 36210 Vigo, Spain
}

\begin{abstract}
Introduction: Previous studies have suggested the use of soluble CD26 (sCD26) as a tumour marker for the detection of colorectal cancer (CRC) and advanced adenomas. The aim of this study was to assess the sCD26 concentration in a large cohort to evaluate its association to epidemiologic parameters and CRC-related symptoms/pathologies.

Subjects and methods: Serum samples were collected from 2,754 putatively healthy individuals with ages ranging from 30-65 years, and with personal or familial history of polyps, CRC and/or CR symptoms. sCD26 levels were measured by ELISA.

Results: No association was found between the sCD26 concentration and age $(<50$ and $\geqslant 50)$, the personal or familial history of polyps or CRC, rectal bleeding, haemorrhoids or diverticula. However, sCD26 was related to non-inflammatory benign pathologies (excluding rectal bleeding, changes in bowel habits, haemorrhoids, diverticula) and to inflammatory benign pathologies.

Discussion: Our results confirm that the sCD26 can be easily offered and evaluated in a large cohort. Additionally, the validation of sCD26 as a tumour marker for screening and case-finding purposes requires a further comparison with an established non-invasive test like the faecal occult blood.
\end{abstract}

Keywords: sCD26, serum levels, colorectal cancer, digestive pathologies, marker

\section{Introduction}

The exoprotease dipeptidyl peptidase IV (DPP-IV, EC 3.4.14.5), also called CD26, is a transmembrane glycoprotein expressed constitutively on a variety of cell types, particularly prostate, kidney, liver and epithelial cells, predominantly in exocrine glands and ab-

\footnotetext{
* Corresponding author: María Páez de la Cadena, Departamento de Bioquímica, Genética e Inmunología, Facultad de Biología, Universidad de Vigo. As Lagoas-Marcosende s/n. 36310 Vigo, Spain. Tel.: +34 986812572; Fax: +34 986812554; E-mail: mpaez@uvigo. es.
}

sorptive epithelia, as well as on lymphocytes [3]. The DPP-IV activity cleaves two $N$-terminal amino acids from polypeptidic chains with proline or alanine in the second position, which otherwise are resistant to most proteases [4]. It participates in the process of dietary protein assimilation and in the cleavage or clipping of many regulatory peptides such as several chemokines, integrins or neuropeptides $[3,4]$. CD26 has been described as the adenosine deaminase (ADA) binding or complexing protein (ADAbp, ADCP) and as a functional receptor for collagen and fibronectin, although its physiological role remains poorly understood $[4,10$, $14,15]$. 
Significant levels of DPP-IV activity have been shown in body fluids such as plasma/serum, cerebrospinal and synovial fluids, semen and urine $[1,6]$. Within the normal human plasma/serum, $90-95 \%$ of the DPP-IV activity has been associated to the relatively high concentration of CD26 $(\sim 600 \mathrm{ng} / \mathrm{mL})$ [1]. sCD26 (soluble CD26) may be shed from the plasma membrane of $\mathrm{CD} 26$ expressing cells by proteolytic cleavage or secretion through exosomes, although lymphocytes and liver bile canaliculi have been proposed as the main source [1,6]. In an oncogenic process, in addition to a plausible involvement in both immunosuppressor and angiogenic mechanisms, the process of shedding might initiate or silence the CD26 involvement in cell-adhesion processes through fibronectin, ADA or collagen binding [6,15-17].

We have reported reduced sCD26 levels in the serum of colorectal cancer (CRC) patients even in early stages of the disease, which suggested its potential use for early diagnosis [2,7]. Subsequent case-control studies suggested that a sCD26 test could improve current noninvasive screening tests recommended for the detection of CRC and advanced adenomas, and could be used in patient monitoring and prognosis [8].

The aim of this study was to measure the sCD26 concentration in a large cohort of presumably healthy individuals and to evaluate its association with epidemiologic parameters as well as certain common digestiverelated symptoms or pathologies. The information obtained from this cohort will complement existing data and will be essential to determine the viability of the sCD26 test for the diagnosis of CRC and advanced adenomas.

\section{Patients and methods}

\subsection{Population}

The study included 2,754 putatively healthy individuals from the company PSA Peugeot Citroën, working at the manufacturing centre in Vigo (Spain). Individuals were mainly males (98\%), with ages ranging from 30 to 65 years. The distribution of the individuals according to their age was as follows: $30-39$ years (0.1\%), $40-49$ years $(1.3 \%), 50-59$ years $(86.8 \%)$ and $60-65$ years $(11.7 \%)$, resulting on an average of 55.5 \pm 3.6 years.

The company's medical service informed employees about the study, and after consent, personal questionnaires were completed for data such as personal and familial history of colorectal polyps or cancer, bowel diseases, symptoms, and smoking status. The final cohort included individuals with personal history of CRC; personal history of a cancer other than CRC; personal history of colorectal polyps; and familial history of cancer and/or colorectal polyps. Regarding their personal history of non-CR cancer, the most common tumours found were prostate, lung, bladder, parotid, ileum and kidney. The symptoms and pathologies recorded were rectal bleeding or faecal blood, changes in bowel habits, haemorrhoids, diverticula, other non-inflammatory benign pathologies including anal fissure, irritable bowel syndrome and spastic colon, and inflammatory bowel disease (colitis or Crohn).

For all the individuals included in the study, informed consent was obtained and anonymity was warranted; all procedures were performed following the tenets of the Helsinki Declaration.

\subsection{Collection of serum samples and determination of sCD26 levels}

Blood was allowed to coagulate at room temperature for $20 \mathrm{~min}$ and centrifuged at $2,000 \mathrm{~g}$ for $15 \mathrm{~min}$. Sera were stored at $-80^{\circ} \mathrm{C}$ until used. Serum levels of the sCD26 were measured with the Human sCD26 ELISA kit (Bender Medsystems; Vienna, Austria) according to the manufacturer's instructions. Colorimetric quantification was performed with a microplate reader (model 550; Bio-Rad, USA) using dual readings at $450 / 570$ $\mathrm{nm}$. The sCD26 concentration was determined from the standard curves.

\subsection{Statistical analysis}

All the statistical tests, except Dunn's, were performed with the SPSS software package (release 16.0). Data was analysed through the ANOVA test; nonparametric analysis of more than two independent samples was done by the Kruskal-Wallis and the Dunn's tests for multiple comparisons.

The rate of sCD26 positive cases was calculated on the basis of a cut-off value of $460 \mathrm{ng} / \mathrm{mL}$ obtained in a previous study for no colorectal pathology, non-inflammatory and inflammatory bowel disease and polyp control populations $v s$. CRC patients (manuscript submitted). A positive value was defined as any value equal or below the cut-off. All the statistical tests were two-sided, and $p$-values $<0.05$ were considered statistically significant. For the pos hoc Dunn's test, significance was achieved if the differences between mean ranks for the pair compared (in absolute values) were larger than the Dunn's contrast. 
Table 1

sCD26 levels $(\mathrm{ng} / \mathrm{mL})$ according to the gender and age groups in the population studied

\begin{tabular}{llccccc}
\hline \multicolumn{2}{c}{$\begin{array}{c}\text { Epidemiologic } \\
\text { information }\end{array}$} & $n$ & $\begin{array}{c}\text { sCD26 } \\
\text { range }\end{array}$ & $\begin{array}{c}\text { sCD26 } \\
\text { median }\end{array}$ & $\begin{array}{c}\text { sCD26 } \\
\text { mean } \pm \text { SD }\end{array}$ & $\begin{array}{c}\text { ANOVA } \\
p \text {-value }\end{array}$ \\
\hline Gender & Male & 2,699 & $118-3,062$ & 522.0 & $554.8 \pm 180.1$ & 0.190 \\
& Female & 55 & $335-1,820$ & 530.0 & $609.6 \pm 244.4$ & \\
\hline Age & Gender & $n$ & sCD26 & sCD26 & sCD26 & ANOVA \\
(years) & & & range & median & mean \pm SD & $p$-value \\
\hline$<50$ & Male & 38 & $422-909$ & 522.0 & $567.7 \pm 142.9$ & $0.496^{\#}$ \\
& Female & 2 & $433-529$ & 481.0 & $481.0 \pm 67.90$ & \\
$\geqslant 50$ & Male & 2,661 & $118-3,062$ & 522.0 & $554.6 \pm 180.6$ & 0.088 \\
& Female & 53 & $335-1,820$ & 544.0 & $614.5 \pm 247.5$ & \\
\hline sCD26 concentration in ng/mL; SD: standard deviation. \\
$\#:$ analysis by ANOVA not allowed; the non-parametric $U$ test showed a $p$-value of 0.321.
\end{tabular}

\section{Results}

\subsection{Soluble CD26 levels in a large cohort}

The sCD26 concentration measured in the sera of the 2,574 individuals (predominantly males over 50 years) showed a normal distribution, ranging from 118 to $3,062 \mathrm{ng} / \mathrm{mL}$ with a mean ( \pm standard deviation) and median value of $555.9 \pm 181.7 \mathrm{ng} / \mathrm{mL}$ and 522.0 $\mathrm{ng} / \mathrm{mL}$, respectively. The range, median and mean sCD26 concentration on the basis of gender and age are shown in Table 1 . Although only $2 \%$ (55 individuals) of the cohort were women compared to the 2,699 men, no statistically significant differences were detected in the sCD26 levels $(p=0.190)$. However, the overall sCD26 mean as well as the median was slightly higher in women than in men. Regarding the age groups $(<50$ years and $\geqslant 50$ years), differences were not observed in the $\mathrm{sCD} 26$ levels $(p=0.496)$. However, a more detailed analysis comparing the age groups 30-39, 40$49,50-59$ and $60-65$ revealed differences in the SCD26 concentration ( $p=0.038$ ). Dunn's test confirmed this difference between all the paired comparisons, except for the 40-49 years and 50-59 years. Additionally we corroborated that, when separating males from females into the former two groups of age, no differences in the sCD26 levels were found ( $<50$ years $p=0.321$ and $\geqslant$ 50 years $p=0.088$ ).

\subsection{Relationship of sCD26 levels with CRC-related epidemiologic parameters}

After confirming no association between the sCD26 levels and the gender and age of the individuals from this cohort, we analysed its relation with the data obtained from the personal questionnaires. Table 2 summarizes for all the variables studied: the sCD26 range, median and mean for the presence or absence of each feature. Fifty five individuals included in this cohort $(2.0 \%)$ referred a personal history of cancer (excluding CRC), while $6(0.2 \%)$ and $80(2.9 \%)$ individuals had been previously diagnosed with CRC or polyps, respectively. No statistically significant differences were detected comparing the sCD26 levels of individuals bearing or not personal history of cancer, CRC or polyps $(p=0.309, p=0.995$ and $p=0.408$, respectively). Regarding the familial history of polyps or cancer, no differences were found either $(p=0.809$ and $p=0.355$, respectively). However, for the personal and familial history of cancer, CRC and polyps, the sCD26 mean in all the cases was slightly lower than the corresponding groups without history.

Levels of the sCD26 were also analysed in relation to certain symptoms (Table 2). Although the individuals from this cohort were presumably healthy, 375 individuals $(13.6 \%)$ had rectal bleeding and 120 individuals $(4.4 \%)$ had changes in bowel habits. The median and mean sCD26 concentration for individuals with rectal bleeding was higher compared to individuals without the symptom, although no significant differences were observed ( $p=0.663$ ). The standard deviation of the mean was almost 1.5 times higher in persons with rectal bleeding, indicating more disperse sCD26 concentration. For individuals with changes in bowel habits, the mean concentration and standard deviation were also higher compared to individuals without the symptom, though the difference was not significant $(p=0.968)$.

Other digestive pathologies were also present in the cohort studied, corresponding to a $13.7 \%$ of the population. The digestive pathologies were classified as non-inflammatory benign pathologies (haemorrhoids, diverticula, irritable bowel syndrome, anal fissure and duodenal ulcer) and inflammatory benign pathologies, as shown in Table 2. An additional group was included for individuals who reported having a digestive pathology, with no further information given. The highest 
Table 2

Relationship between personal history, family history and symptoms with the sCD26 levels (ng/mL)

\begin{tabular}{|c|c|c|c|c|c|c|}
\hline Personal or family history & & $\bar{n}$ & $\begin{array}{l}\mathrm{sCD} 26 \\
\text { range }\end{array}$ & $\begin{array}{l}\mathrm{sCD} 26 \\
\text { median }\end{array}$ & $\begin{array}{c}\mathrm{sCD} 26 \\
\text { mean } \pm \mathrm{SD}\end{array}$ & $\begin{array}{l}\text { ANOVA } \\
p \text {-value }\end{array}$ \\
\hline \multirow[t]{2}{*}{ P. history of cancer } & No & 2,699 & $118-3,062$ & 522.0 & $556.5 \pm 182.6$ & 0.309 \\
\hline & Yes & 55 & $238-785$ & 532.0 & $526.0 \pm 129.8$ & \\
\hline \multirow[t]{2}{*}{ P. history of CRC } & No & 2,748 & $118-3,062$ & 522.0 & $556.0 \pm 181.8$ & 0.995 \\
\hline & Yes & 6 & $334-713$ & 461.0 & $477.8 \pm 127.2$ & \\
\hline \multirow[t]{2}{*}{ P. history of polyps } & No & 2,674 & $118-3,062$ & 513.0 & $556.4 \pm 181.8$ & 0.408 \\
\hline & Yes & 80 & $252-1,277$ & 523.0 & $537.8 \pm 178.1$ & \\
\hline \multirow[t]{2}{*}{ F. history of polyps } & No & 2,651 & $118-3,062$ & 522.0 & $556.0 \pm 183.4$ & 0.809 \\
\hline & Yes & 103 & $307-1,004$ & 516.0 & $553.3 \pm 130.0$ & \\
\hline \multirow[t]{2}{*}{ F. history of cancer } & No & 2,026 & $118-3,062$ & 521.5 & $559.4 \pm 193.6$ & 0.355 \\
\hline & Yes & 728 & $164-1,169$ & 523.0 & $546.0 \pm 143.0$ & \\
\hline Symptoms or pathologies & & $n$ & $\begin{array}{l}\mathrm{sCD} 26 \\
\text { range }\end{array}$ & $\begin{array}{l}\mathrm{sCD} 26 \\
\text { median }\end{array}$ & $\begin{array}{c}\mathrm{sCD} 26 \\
\text { mean } \pm \mathrm{SD}\end{array}$ & $\begin{array}{l}\text { ANOVA } \\
p \text {-value }\end{array}$ \\
\hline \multirow[t]{2}{*}{ Rectal bleeding } & No & 2,379 & $118-2,648$ & 522.0 & $552.9 \pm 171.2$ & 0.663 \\
\hline & Yes & 375 & $288-3,062$ & 531.0 & $574.9 \pm 237.4$ & \\
\hline \multirow[t]{2}{*}{ Change bowel habits } & No & 2,634 & $118-3,062$ & 522.0 & $555.4 \pm 179.0$ & 0.968 \\
\hline & Yes & 120 & $318-2,349$ & 517.0 & $566.9 \pm 234.3$ & \\
\hline \multirow[t]{2}{*}{ Haemorrhoids } & No & 2,661 & $118-3,062$ & 522.0 & $554.4 \pm 177.9$ & 0.203 \\
\hline & Yes & 93 & $337-2,349$ & 531.0 & $597.1 \pm 266.4$ & \\
\hline \multirow{2}{*}{ Diverticula } & No & 2,751 & $118-3,062$ & 522.0 & $555.8 \pm 181.8$ & 1.000 \\
\hline & Yes & 3 & $485-712$ & 583.0 & $593.3 \pm 113.9$ & \\
\hline \multirow[t]{2}{*}{ Irritable bowel syndrome } & No & 2,740 & $118-3,062$ & 519.0 & $550.4 \pm 181.0$ & $<0.001 *$ \\
\hline & Yes & 14 & $346-916$ & 495.5 & $551.7 \pm 164.8$ & \\
\hline \multirow[t]{2}{*}{ Anal fissure } & No & 2,744 & $118-3,062$ & 518.0 & $549.5 \pm 180.2$ & $<0.001 *$ \\
\hline & Yes & 10 & $471-1,169$ & 548.5 & $652.8 \pm 224.1$ & \\
\hline \multirow[t]{2}{*}{ Duodenal ulcer } & No & 2,745 & $118-3,062$ & 518.0 & $550.7 \pm 180.9$ & 0.0916 \\
\hline & Yes & 9 & $259-733$ & 537.0 & $516.7 \pm 168.4$ & \\
\hline \multirow[t]{2}{*}{ Inflammatory benign pathologies } & No & 2,749 & $118-3,062$ & 522.0 & $555.9 \pm 181.8$ & $<0.001 *$ \\
\hline & Yes & 5 & $425-808$ & 519.0 & $555.4 \pm 154.7$ & \\
\hline \multirow[t]{2}{*}{ Other not specified digestive pathologies } & No & 2,377 & $118-3,062$ & 519.0 & $572.0 \pm 195.8$ & 0.117 \\
\hline & Yes & 243 & $252-2,052$ & 538.0 & $552.5 \pm 176.1$ & \\
\hline
\end{tabular}

P: personal; F: family; *statistically significant $(p<0.05)$.

sCD26 mean was observed within the 93 individuals with haemorrhoids, who like the individuals with rectal bleeding and changes in bowel habits, showed a standard deviation over $200 \mathrm{ng} / \mathrm{mL}$. Individuals with diverticula showed the highest median, with a mean similar to the haemorrhoid group. Regarding pathologies as irritable bowel syndrome and anal fissure, as well as the inflammatory benign pathologies, and in contrast to the rest of the groups, statistically significant differences in the sCD26 levels were detected $(p<0.001)$. Differences were not observed for individuals with other not specified benign pathologies.

Information concerning the smoking status was also obtained from the cohort (Table 3). A $63.8 \%$ of the individuals were non-smokers, $27.8 \%$ were current smokers while $8.4 \%$ were former smokers. Current smokers showed the lowest median and mean sCD26 concentration, while the highest values corresponded to former smokers. The Kruskal-Wallis test revealed statistically significant differences in the sCD26 levels between the three groups considered $(p=0.013)$. Ac- cording to the Dunn's test, differences exist between current smokers and non-smokers $(71.5>3.9)$, current smokers and former smokers $(165.2>6.8)$ and nonsmokers and former smokers $(93.7>6.4)$. Additionally, we tested if the number of cigarettes per day was also related to the $\mathrm{SCD} 26$ concentration: according to the groups 1-5, 6-10, 10-20 and > 20 cigarettes per day, there was no significant difference. Further analyses with the Dunn's test showed differences in the sCD26 between the groups 1-5 vs. 6-10, and any of the groups vs. $>20$ cig/day.

\section{Discussion}

In previous works we observed that the soluble CD26 levels were diminished in CRC patients as compared to healthy donors [2,7] suggesting its utility in the early diagnosis of CRC and advanced adenomas (manuscript submitted). In this work we measured the sCD26 concentration in the sera of a large cohort of apparently 
Table 3

Relationship between tobacco smoking and the sCD26 levels $(\mathrm{ng} / \mathrm{mL})$

\begin{tabular}{lccccc}
\hline Smoking status & $n$ & $\begin{array}{c}\text { sCD26 } \\
\text { range }\end{array}$ & $\begin{array}{c}\text { sCD26 } \\
\text { median }\end{array}$ & $\begin{array}{c}\text { sCD26 } \\
\text { mean } \pm \text { SD }\end{array}$ & $\begin{array}{c}\text { Kruskal-Wallis } \\
p \text {-value }\end{array}$ \\
\hline Non-smoker & 1,758 & $118-3,062$ & 524.0 & $557.2 \pm 175.7$ & 0.013 \\
Former smoker & 230 & $189-1,448$ & 545.0 & $576.8 \pm 192.6$ & \\
Current smoker & 766 & $164-2,648$ & 510.0 & $546.6 \pm 191.3$ & \\
1-5 cig/day & 238 & $274-2,349$ & 505.5 & $550.3 \pm 184.0$ & 0.393 \\
6-10 cig/day & 153 & $176-2,648$ & 516.0 & $547.1 \pm 231.5$ & \\
10-20 cig/day & 256 & $164-2,052$ & 506.0 & $534.7 \pm 180.1$ & \\
$>$ 20 cig/day & 119 & $288-1,244$ & 523.5 & $568.6 \pm 173.0$ & \\
\hline
\end{tabular}

Cig/day: cigarettes smoked per day.

healthy individuals to evaluate its relation with certain epidemiologic variables and to establish the feasibility of its use as a test for the diagnosis of CRC and premalignant lesions.

Since this is the first time sCD26 was measured in a large cohort with these characteristics, we corroborated that the concentration of this glycoprotein in serum has a normal distribution. The mean sCD26 concentration in this cohort corresponded to $555.9 \pm 181.7 \mathrm{ng} / \mathrm{mL}$, similar to that previously reported for 52 healthy donors $(559.7 \pm 125.5 \mathrm{ng} / \mathrm{mL})$ [7]. However, the range in this large cohort was considerably broad compared to that of the healthy donors (118-3,062 ng/mL and 273-863 $\mathrm{ng} / \mathrm{mL}$, respectively) [7], resulting in a larger standard deviation. In relation to the data reported by the kit manufacturer in 38 apparently healthy donors (mean: $591 \pm 179 \mathrm{ng} / \mathrm{mL}$; range: $296.0-1,110 \mathrm{ng} / \mathrm{mL}$ ), the standard deviation is comparable in both cohorts, although the mean sCD26 concentration is higher in the kit-reported healthy population.

The analysis of the SCD26 concentration in the large cohort studied showed no association with the gender of the individuals, though it should be noticed there was a small number of females in this cohort and thus this conclusion should be taken cautiously. However, women tend to have higher median and mean sCD26 levels despite the narrower range of concentration compared to males, in contrast to that found when enzymatic activity was measured in plasma or serum $[9,10]$. This difference can be explained by putative changes in the glycosylation pattern (leading to a lack of immunorecognition of sCD26), the purported presence of the DPP-IV activator attractin, or the secretion of DPP-II [4,10].

Regarding age, no differences were observed in this cohort comparing the sCD26 levels in individuals $<50$ and $\geqslant 50$ years of age. Although the analysis between decades revealed certain differences in the sCD26 levels, the decrease in the glycoprotein concentration between the fourth, fifth and sixth decade of life is very slight and would not interfere with the sCD26 test applied to a screening population, especially older than 50 years. Concerning the DPP-IV enzymatic activity present in serum, it was previously reported for a cohort of 481 individuals with ages ranging from 19 to 61 years a relationship with age $[9,10]$.

On the other hand, no association was found between the sCD26 concentration and the personal or familial history of polyps, CRC or cancer other than CR. Although the mean SCD26 levels were somewhat diminished in individuals with these antecedents.

Regarding digestive diseases, the groups with irritable bowel syndrome, anal fissure and inflammatory benign pathologies had an association with the sCD26. Although the biological role of the sCD26 has not been completely elucidated yet, it has been proposed to be multifunctional. Some of the functions becoming quite clear are the activation-deactivation of some chemokines [5,13] and a T-cell activation through a CD86 upregulation [14], which supports sCD26 has a relationship with the immune response and/or inflammation. On the contrary, the relationship of the sCD26 levels with irritable bowel syndrome and anal fissure is not straightforward, and more details on the biological functions of the sCD26 are needed to find a reasonable explanation. On the other hand, sCD26 levels were found to be related to the smoking status, smokers showing the lowest mean although no clear association regarding the amount of cigarettes smoked per day was observed. Tobacco smoking was also included in our analysis due to the consistent association between smoking and a significantly increased risk of CRC [12, $18]$.

The absence of correlation between all the parameters analysed, with special interest on the personal and familial history, together with rectal bleeding and changes in bowel habits, confirm that the sCD26 test can be easily offered and evaluated in a large population cohort at least predominantly formed by males over 50 years, which coincides with one of the popu- 
lation sectors considered at average risk for CRC [11]. The information elucidated in this study appears to be essential for the future application of the sCD26 test for screening and case-finding purposes. The next step in the validation of this molecule as a tumour marker is undoubtedly a screening study in average-risk individuals, perhaps along with the comparison of a faecal occult blood test.

Moreover, it should be noted that the alteration of the sCD26 levels as a tumour marker for early diagnosis of $\mathrm{CRC}$ and pre-malignant lesions has an independent origin to that of faecal blood appearance and, if not to the tumourigenic locus, at least to the tumourigenic tissue. In addition, as it seems immune-related, the sCD26 decrease in the plasma of patients should be sooner in the adenoma-carcinoma development compared to the presence of faecal blood.

\section{Acknowledgements}

We are indebted to the Medical Service of PSA Peugeot Citroën (Vigo) for their contribution to the study, especially Dr. J.A. Díaz-González and Dr J.L. Martínez-Murillo. We also thank Beatriz Otero for technical assistance.

\section{References}

[1] T. Andrieu, V. Thibault, I. Malet, J. Laporte, B. Bauvois, H. Aqut and A. Cahour, Similar increased serum dipeptidyl peptidase IV activity in chronic hepatitis $\mathrm{C}$ and other viral infections, J Clin Virol 27 (2003), 59-68.

[2] D. Ayude, M. Paez de la Cadena, O.J. Cordero, M. Nogueira, J. Ayude, A. Fernández-Briera and F.J. Rodríguez-Berrocal, Clinical interest of the combined use of serum CD26 and alpha-L-fucosidase in the early detection diagnosis of colorectal cancer, Dis Markers 19 (2004), 267-272.

[3] L.L. Baggio and D.J. Drucker, Biology of incretins: GLP-1 and GIP, Gastroenterology 132 (2007), 2131-2157.

[4] E. Boonacker and C.J.F. Van Noorden, The multifunctional or moonlighting protein CD26/DPPIV, Eur J Cell Biol 82 (2003), 53-73.

[5] N. Busso , N. Wagtmann, C. Herling, V. Chobaz-Péclat, A. Bischof-Delaloye, A. So and E. Grouzmann, Circulating CD26 is negatively associated with inflammation in human and experimental arthritis, Am J Pathol 166 (2005), 433-442.

[6] H.C. Cheng, M. Abdel-Ghany and B.U. Pauli, A novel consensus motif in fibronectin mediates dipeptidyl peptidase IV adhesion and metastasis, J Biol Chem 278 (2003), 2460024607.
[7] O.J. Cordero, D. Ayude, M. Nogueira, F.J. Rodríguez-Berrocal and M. Páez de la Cadena, Preoperative serum CD26 levels: diagnostic efficiency and predictive value for colorectal cancer, Br J Cancer 83 (2000), 1139-1146.

[8] O.J. Cordero, L. De Chiara, Y. Lemos-González, M. Páez de la Cadena and F.J. Rodríguez-Berrocal, How the measurements of a few serum markers can be combined to enhance their clinical values in the management of cancer, Anticancer Res 28 (2008), 2333-2341.

[9] C. Durinx, H. Neels, J.C. Van der Auwera, K. Naelaerts, S. Scharpe and I. De Meester, Reference values for plasma dipeptidyl peptidase IV activity and their association with other laboratory parameters, Clin Chem Lab Med 39 (2001), 155-159.

[10] A.M. Lambeir, C. Durinx, S. Scharpé and I. De Meester I, Dipeptidyl-peptidase IV from bench to bedside: an update on structural properties, functions, and clinical aspects of the enzyme DPP IV, Crit Rev Clin Lab Sci 40 (2003), 209-294.

[11] B. Levin, D.A. Lieberman, B. McFarland, R.A. Smith, D. Brooks, K.S. Andrews, C. Dash, F.M. Giardiello, S. Glick, T.R. Levin, P. Pickhardt, D.K. Rex, A. Thorson and S.J. Winawer, American Cancer Society Colorectal Cancer Advisory Group, US Multi-Society Task Force and American College of Radiology Colon Cancer Committee, Screening and surveillance for the early detection of colorectal cancer and adenomatous polyps, 2008: a joint guideline from the American Cancer Society, the US Multi-Society Task Force on Colorectal Cancer, and the American College of Radiology, $C A$ Cancer J Clin 58 (2008), 130-160

[12] P.S. Liang, T.Y. Chen and E. Giovannucci, Cigarrette smoking and colorectal cancer incidence and mortality: systematic review and meta-analysis, Int J Cancer 124 (2009), 2406-2415.

[13] M.G. Narducci, E. Scala, A. Bresin, E. Caprini, M.C. Picchio, D. Remotti, G. Ragone, F. Nasorri, M. Frontani, D. Arcelli, S. Volinia, G.A. Lombardo, G. Baliva, M. Napolitano and G. Russo, Skin homing of Sezary cells involves SDF-1-CXCR4 signaling and down-regulation of CD26/dipeptidylpeptidase IV, Blood 107 (2006), 1108-1115.

[14] K. Ohnuma, T. Yamochi, M. Uchiyama, K. Nishibashi, S. Iwata, O. Hosono, H. Kawasaki, H. Tanaka, N.H. Dang and C. Morimoto, CD26 mediates dissociation of Tollip and IRAK-1 from caveolin-1 and induces upregulation of CD86 on antigenpresenting cells, Mol Cell Biol 25 (2005), 7743-7757.

[15] V. Preller, A. Gerber, S. Wrenger, M. Togni, D. Marguet, J. Tadje, U. Lendeckel, C. Röcken, J. Faust, K. Neubert, B. Schraven, R. Martin, S. Ansorge, S. Brocke and D. Reinhold, TGF-beta1-mediated control of central nervous system inflammation and autoimmunity through the inhibitory receptor CD26, J Immunol 178 (2007), 4632-4640.

[16] A. Sedo, J. Stremenova, P. Busek and S. Duke-Cohan, Dipeptidyl peptidase-IV and related molecules: markers of malignancy? Expert Opin Med Diagn 2 (2008), 1-13.

[17] R.M. Strieter, J.A. Belperio, M.D. Burdick, S. Sharma, S.M. Dubinett and M.P. Keane, CXC chemokines: angiogenesis, immunoangiostasis, and metastases in lung cancer. Ann NY Acad Sci 1028 (2004), 351-360.

[18] K.K. Tsoi, C.Y. Pau, W.K. Wu, F.K. Chan, S. Griffiths and J.J. Sung, Cigarrette smoking and the risk of colorectal cancer: a meta-analysis of prospective cohort studies, Clin Gastroenterol Hepatol 7 (2009), 682-688. 


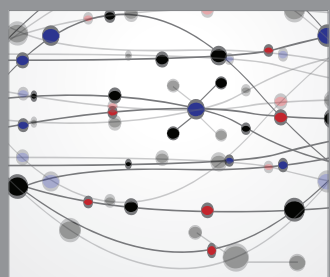

The Scientific World Journal
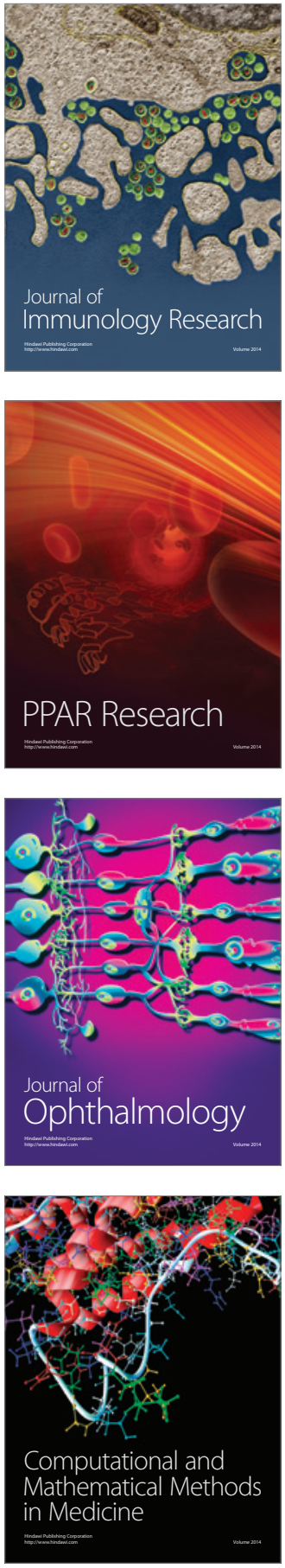

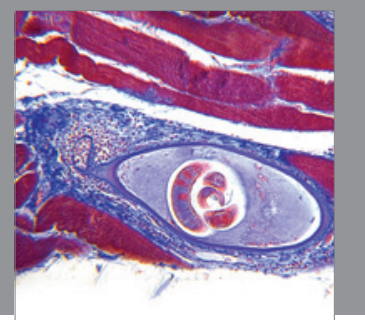

Gastroenterology

Research and Practice
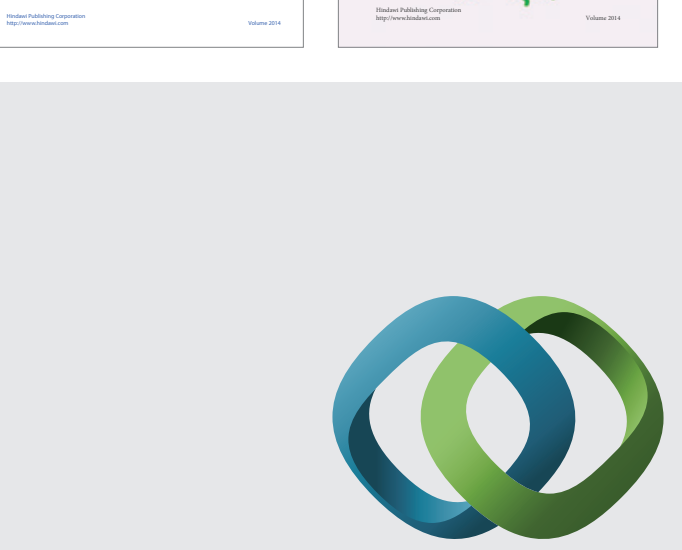

\section{Hindawi}

Submit your manuscripts at

http://www.hindawi.com
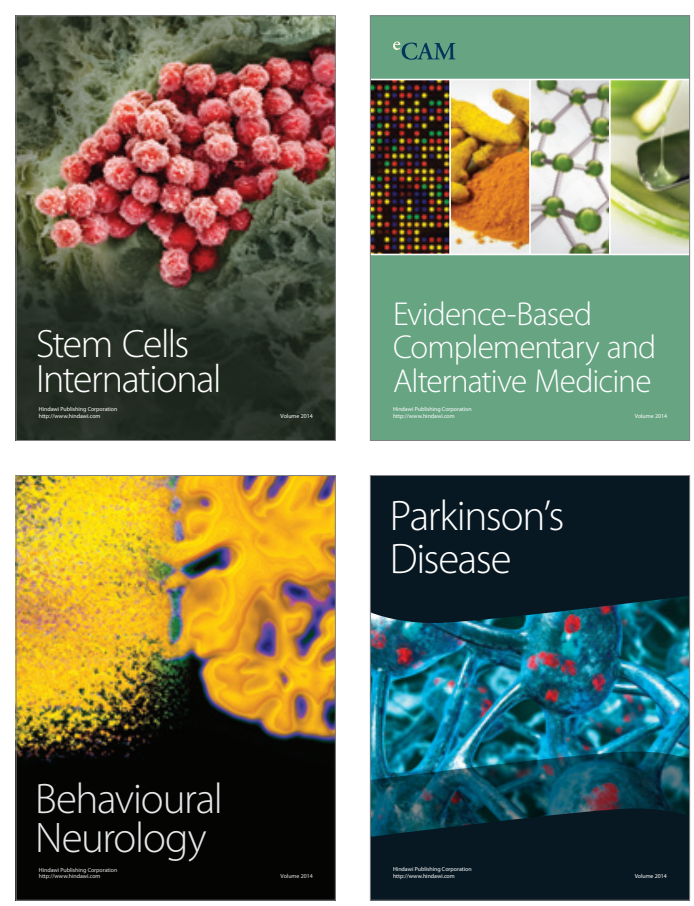

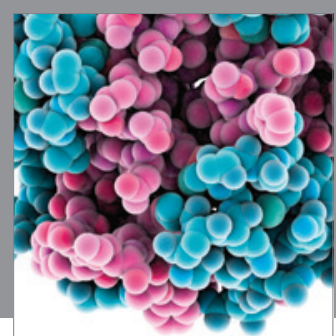

Journal of
Diabetes Research

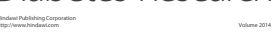

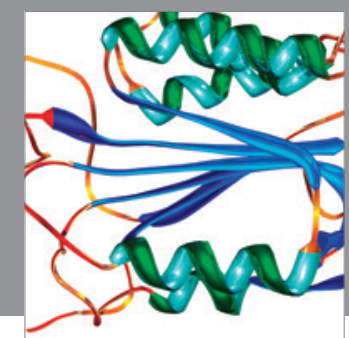

Disease Markers
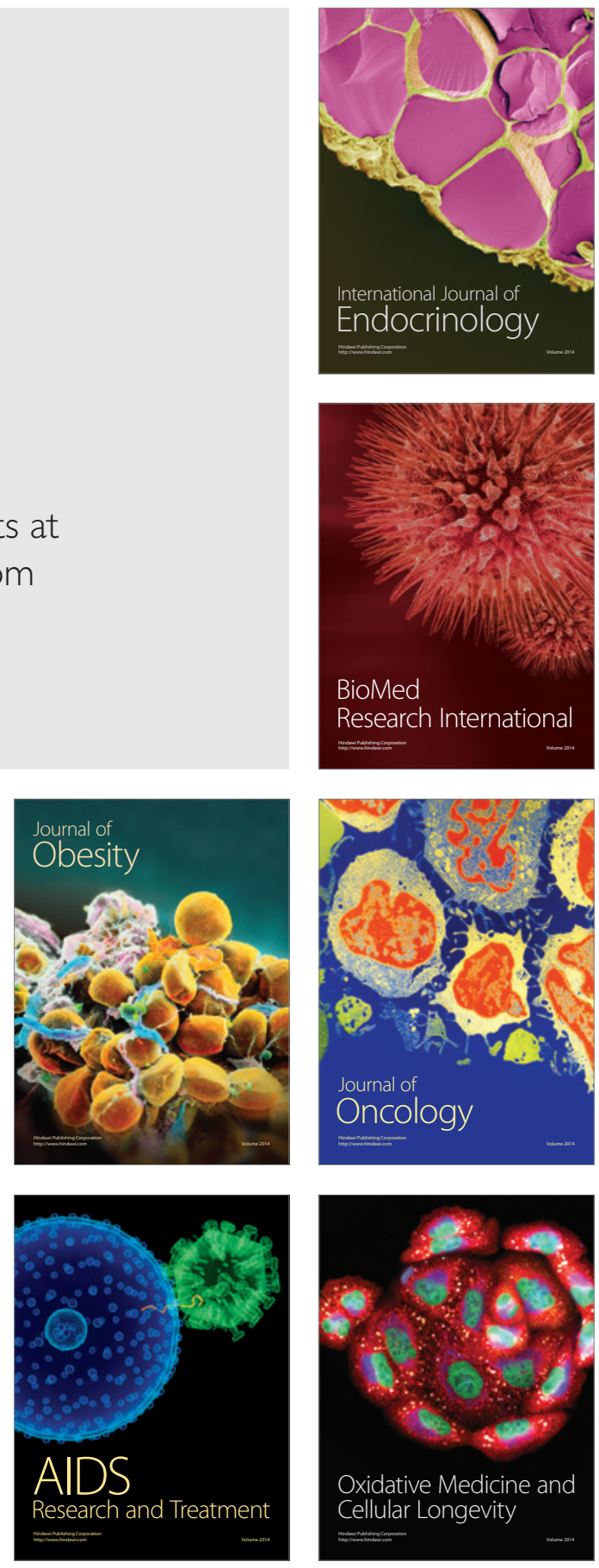